\title{
Postgraduate Surgical Education in Bhutan
}

\author{
Sonam Dargay ${ }^{1,2}$ (D) $\cdot$ Tashi Tenzin $^{3} \cdot$ Karma Tenzin $^{4}$
}

Received: 27 September 2021 / Accepted: 1 November 2021 /Published online: 26 November 2021

(c) Association of Surgeons of India 2021

\begin{abstract}
Postgraduate medical education in Bhutan began in 2014 which marked a new era in the medical education in the country. From a mere handful of surgeons in 2003 to the numbers today, general surgical services have come a long way in Bhutan. Medical education has progressed tremendously to adoption of modern medical educational methods promoting objectivity in all aspects. This article dwells with the historical perspective as well as the state of the general surgical education and the services in Bhutan. It is the first of its kind of article to be written.
\end{abstract}

Keywords Postgraduate medical education $\cdot$ Bhutan $\cdot$ General surgical education

\section{Background}

Bhutan is a small landlocked country with a population of just over 700,000. Healthcare, both modern and traditional medicine, is free in Bhutan as enshrined in the constitution [1]. Therefore, government revenue is the predominant source of health financing.

It was during the First Five-Year Development Plan (1961-1966) that Bhutan's road to modern health care began in 1961 with two hospitals, two doctors, and two nurses. Since then, Bhutan has witnessed significant progress in the health and well-being of her population. Bhutan is one of the few countries who are on the path to fulfilling sustainable development goals. Since introducing planned socioeconomic development, life expectancy has increased to 69.5 years in 2014 from a mere 32.4 years in 1960 [2].

The country has a three-tiered health system, three tertiary centers located strategically in the west, east, and central regions of the country, secondary health centers.

(20-60-bed hospitals) in every district, and primary care centers (primary health centers) and outreach clinics at the

Sonam Dargay

sdargay@jdwnrh.gov.bt

1 Department of Surgery, JDWNRH, Thimphu, Bhutan

2 KGUMSB, Thimphu, Bhutan

3 Department of Surgery, JDWNRH/Faculty of Post-Graduate Medicine (FoPGM), KGUMSB, Thimphu, Bhutan

4 Faculty of Post-Graduate Medicine (FoPGM), KGUMSB, Thimphu, Bhutan community level. Bhutan not only provides free health care to her citizens within the country but also refers patients outside for health services that are not available inside. For example, cases like renal transplants and cardiac surgeries are referred to India with the treatment and travel costs being borne by the government.

\section{Health Human Resource in Bhutan}

As of 2021, according to the Ministry of Health of Bhutan, the country has over 5300 health workers [3]. Until the early 2000 s, the country had a single national general surgeon who was supported from time to time by visiting expatriate surgeons. This lack in numbers was primarily due to the fact that Bhutan was totally dependent on foreign medical institutes (in India, Bangladesh, and Sri Lanka, among others) for both undergraduate and postgraduate medical training. The strict admission criteria in these institutes coupled with considerable delays in admission resulted in fewer candidates being sent for medical education. By 2008, Bhutan had three national general surgeons who performed both general surgeries and subspecialty surgeries. Two of them had been trained in India while the third surgeon graduated from Bangladesh. At the time of writing of this article, Bhutan can now boast of eighteen surgeons. Despite this, the most serious concern that still remains even today is the shortage of doctors and specialist doctors. In order to address 
this concern and to find a more sustainable solution, the Khesar Gyalpo University of Medical Sciences was established in 2014 [4].

\section{Establishment of a Medical University}

The Royal Government of Bhutan established the Khesar Gyalpo University of Medical Sciences (KGUMSB) of Bhutan in 2014 as an "overarching university for existing Institutions engaged in medical and health care education and training programs in the country and new institutions established hereinafter."

The university has three faculties/institutes under its umbrella, namely Faculty of Nursing and Public Health, Faculty of Traditional Medicine, and Faculty of Postgraduate Medicine. Although the university was initially established in order to start the MBBS program, due to numerous challenges, a postgraduate program was deemed to be more feasible.

The mandate of the university is to provide quality medical and health education in Bhutan to address the shortage of healthcare workers and to address long-term needs of the training of the healthcare workforce at various levels (diplomas, bachelor's to $\mathrm{PhD}$ degrees, and provision of continued medical education and specialized short-term trainings). The university aspires to produce graduates who are not only locally competent but also job ready for the global market in the long run by ensuring that students learn sound fundamentals in the medical sciences, acquire good communication skills and research skills, and learn the principles of gross national happiness and medical humanities. The university also aims to contribute towards the national vision of making Bhutan a knowledge-based society.

\section{Surgical Postgraduate Medical Education and Training in Bhutan}

The Postgraduate Medical Education Center (renamed as the Faculty of Postgraduate Medicine in 2016) introduced postgraduate training in general surgery, ophthalmology, anesthesiology, pediatrics, and obstetrics and gynecology in July 2014. The curricula were developed by a team of local experts, in line with the Bhutan Medical and Health Council's "Postgraduate Medical Education Regulations 2014" [5]. The existing curricula were being challenged by the increasing need to transform medical education to meet the evolving and specific health needs of the communities. One important need that was felt was the "adoption of competency-based curricula that were responsive to changing needs" www.fopgm.edu.bt.

Over the years, other disciplines joined in and as of July 2021, the Faculty of Postgraduate Medicine offers eleven postgraduate programs https://knowledgeplus.nejm.org/ blog/exploring-acgme-core-competencies/. At this point, there are 64 residents undergoing 4-year full-time residency programs. These residents are primarily trained at the 380bed multi-specialty teaching hospital, Jigme Dorji Wangchuck National Referral Hospital. The residents are also sent for their electives to the two regional referral hospitals, each with a 150-bed capacity.

The existing curriculum of postgraduate in general surgery is a "competency-based curriculum" with a robust, comprehensive, and continuous assessment system in the form of workplace-based assessment. The focus is on building appropriate "competencies" in the new curriculum. This has resulted in general surgery graduates performing well in their places of posting, with the university receiving good feedback from the field as well as from the stakeholders.

To ensure the quality of teaching-learning and also for greater exposure in different settings, the university has developed linkages with many renowned institutes and universities from abroad for various purposes such as elective posting of residents, faculty exchange program, and inviting visiting faculties for collaboration as well as external examiners.

\section{General Surgery Postgraduate Curriculum}

The curriculum is based on the Accreditation Council for Graduate Medical Education (ACGME) which expects residents to obtain competency in the following six core competencies to the level expected of twenty-first-century general specialists https://knowledgeplus.nejm.org/blog/exploringacgme-core-competencies/:

- Patient care (PC)

- Medical knowledge (MK)

- Interpersonal and communication skills (ICS)

- Professionalism (P)

- Practice-based learning and improvement (PBLI)

- Systems-based practice (SBP)

The curriculum which is focused on competency-based medical education is structured over 4 years to give the residents adequate learning experiences to develop and internalize all the skills necessary to manage all kinds of surgical problems. During the 4 years, the residents are given greater responsibility in an incremental manner so that by the fourth year, they are able to function independently. The Entrustable Professional Activities (EPA) section also plays 
a major role in preparing the graduates to become competent in shouldering their responsibilities.

Besides the clinical training, the residents are also exposed to various forms of educational strategies and are provided with opportunities for undergoing electives in universities outside the country so as to give them exposure in subspecialties, primarily in those not available in the country. Similarly, they are also posted to regional referral hospitals in the country in order to enhance their learning opportunities.

\section{Uniqueness in Curriculum}

\section{Workplace-Based Assessment (WPBA)}

The residents are required to maintain a proper portfolio to record all the educational activities/procedures performed over the 4 years. The curriculum emphasizes continuous learning through continual faculty and peer feedback with the use of workplace-based assessment tools (WPBA) to facilitate proper learning and inculcate a culture of selfdirected learning, critical thinking, and ultimately life-long learning.

In the current practice, four tools are being used, namely (a) Case-Based Discussion (CbD), (b) Mini-Clinical Examination (Mini-Cex), (c) Direct Observation of Procedural Skills (DOPS), and (d) $360^{\circ}$ Feedback/Multisource Assessments [6].

\section{Quality Improvement Project}

During the final year $\left(7^{\text {th }}\right.$ term), residents are required to conduct one quality improvement project in their own departments.

\section{Medical Humanities}

The postgraduate residents are also provided with a medical humanities workshop during their 4 years of study. This was primarily designed with the objective of helping them develop required "appropriate communication" skills to be used as professionals.

\section{Residents as Teacher}

The residents also are provided with training on basic pedagogy. This was again designed bearing in mind that they invariably are expected to teach many categories of health workers such as interns, nurses, and others.

\section{Course Structure}

During the 4-year course, surgical residents are also allocated a monthly rotational posting in related fields like anesthesiology, obstetrics and gynecology, and orthopedics. Unlike other multi-specialty hospitals where the subspecialties are in the different units, the surgical department of our teaching hospital has subspecialties like urology, neurosurgery, oncosurgery, pediatric surgery, and endoscopic units under one department. This enables residents to have access to most of the subspecialties on a daily basis. However, for other subspecialties not available in Bhutan, residents are posted out to other affiliated institutes outside the country. However, since 2020, due to the COVID-19 pandemic, the practice of ex-country elective postings has been seriously hampered.

The university also introduced pedagogical training to the faculties. This has opened new opportunities for the faculties to learn how to teach young adults in a more modernized manner.

While teaching and learning initially were based on humble traditional methods, the university is now moving towards technology-based medical education. Various simulation-based skills labs like endoscopy, colonoscopy, laparoscopy, temporal bone dissection, and phacoemulsification are in the pipeline. These facilities will help our residents learn and train better as surgeons without having to practice as a novice directly on a patient and without putting patients at risk. This will also provide a platform for residents to spend any free time honing their surgical skills.

\section{Challenges in the Implementation of the New Curriculum}

The introduction of the WPBA has been a huge challenge as it was something new and there was resistance to change from all stakeholders. However, gradually over time, both the faculties and residents have observed that it offered more advantages than disadvantages. The cardinal feature that brought significant change in the teaching-learning environment was the feedback system in WPBA.

\section{Assessment System in Brief}

Examination system and overview 


\begin{tabular}{|c|c|c|c|c|c|c|}
\hline & \multirow[t]{2}{*}{ Examinations } & \multirow[t]{2}{*}{ Schedule } & \multicolumn{2}{|l|}{ Components } & \multirow[t]{2}{*}{ Total marks } & \multirow[t]{2}{*}{$\%$ weightage ${ }^{*}$} \\
\hline & & & Written & Practical & & \\
\hline \multirow[t]{2}{*}{$\begin{array}{l}\text { Term } \\
1-2\end{array}$} & Institute Examination I & \multirow[t]{2}{*}{ End of term 1} & $\begin{array}{l}\text { Paper I-V (each } \\
\text { paper) } \\
\text { 1. MCQ: } 50 \% \\
\text { 2. SAQ }=5 \text { marks } \\
* 10\end{array}$ & $\begin{array}{l}\text { OSPE }=20 \\
\text { stations } * \\
3 \text { min }=100 \\
\text { marks }\end{array}$ & 600 & \multirow[t]{2}{*}{$\begin{array}{r}\text { Exams }=10 \% \\
\quad(\mathrm{CA}=5 \%)^{*}\end{array}$} \\
\hline & $\begin{array}{l}\text { Continuous assessment } \\
\text { (CA) }\end{array}$ & & \multicolumn{2}{|c|}{$\begin{array}{l}\text { Mini-Cex, DOPS, CBD, } 360^{\circ} \text { feed- } \\
\text { back, logbook/portfolio }\end{array}$} & 100 & \\
\hline \multirow[t]{2}{*}{$\begin{array}{l}\text { Term } \\
3-4\end{array}$} & \multicolumn{2}{|l|}{$\begin{array}{l}\text { Continuous assessment } \\
\text { (CA) }\end{array}$} & \multicolumn{2}{|c|}{$\begin{array}{l}\text { Mini-Cex, DOPS, CBD, OSLER, } 360^{\circ} \\
\text { feedback, logbook }\end{array}$} & 100 & \multirow[t]{2}{*}{$\begin{array}{l}(\mathrm{CA}=5 \%)^{*} \\
\text { Exams }=20 \%\end{array}$} \\
\hline & Institute Examination II & End of term 4 & $\begin{array}{l}\text { Paper I and II } \\
\text { (each paper) } \\
\text { 1. MCQs: } 50 \\
\text { marks } \\
\text { 2. SAQ }=5 \text { marks } \\
* 6 \\
\text { 3. SLEQ }=10 \\
\text { marks } 2\end{array}$ & $\begin{array}{l}\text { 1. OSCE, } 10 \\
\text { stations }(5 \mathrm{~min} \\
\text { each) } 100 \text { marks } \\
\text { 2. Short case }(2) \text { : } \\
50 \text { marks * } 2 \\
\text { 3. Long case } \\
\text { (1): } 100 \text { marks } \\
\text { (OSLER) }\end{array}$ & 400 & \\
\hline \multirow[t]{2}{*}{$\begin{array}{l}\text { Term } \\
5-6\end{array}$} & \multicolumn{2}{|l|}{$\begin{array}{l}\text { Continuous assessment } \\
\text { (CA) }\end{array}$} & \multicolumn{2}{|c|}{$\begin{array}{l}\text { Mini-Cex, DOPS, CBD, OSLER, } \\
\text { 360-degree feedback, log book/ } \\
\text { portfolio }\end{array}$} & 100 & \multirow[t]{2}{*}{$\begin{array}{l}(\mathrm{CA}=5 \%)^{*} \\
\text { Thesis }=20 \%\end{array}$} \\
\hline & Submission of thesis & End of term 6 & \multicolumn{2}{|c|}{$\begin{array}{l}\text { 1. Thesis content and presentation: } 25 \\
\text { marks each } \\
\text { 2. Oral/viva voce: } 25 \text { marks }\end{array}$} & 100 & \\
\hline $\begin{array}{l}\text { Term } \\
7-8\end{array}$ & $\begin{array}{l}\text { Continuous assessment } \\
\text { (CA) }\end{array}$ & & \multicolumn{2}{|c|}{$\begin{array}{l}\text { Quality improvement project during } \\
\text { the } 7^{\text {th }} \text { term (July-December) with } \\
\text { report writing and submission to the } \\
\text { dean's office through the supervisor } \\
\text { for the QI project }\end{array}$} & 100 & $(\mathrm{CA}=5 \%)^{*}$ \\
\hline
\end{tabular}

\section{Specific to General Surgery Education}

In 2014, a major milestone was achieved when the general surgery program started with two residents and five faculty members. The mission of the surgery postgraduate medical education is to ensure that all surgical residents possess sound knowledge, skills and experience, and the correct attitude through uniform high-quality training to enable them to become competent, compassionate, and confident surgeons providing the highest level of quality care.

The general surgery training in Bhutan is all about emphasizing good hands-on training unlike the institutes where our older-generation surgeons got trained where hands-on practice was unheard of. The residents are taught in a stepwise fashion till they are able to perform a procedure or surgery independently without causing harm to the patients. The graduation of the first general surgeon in 2018 marked a new era in medical education. It was a proud moment not only for the faculty but also for Bhutan as we had succeeded in producing our first home-grown surgeon. It marked a new beginning for our country towards realizing the goal of self-sufficiency in human resources such as in the field of surgery. Since then, seven general surgeons have graduated from KGUMSB. As of July
2021, there are seven more postgraduate residents undergoing their medical education in surgery. Going by the progress made thus far, Bhutan should be having adequate general surgeons in the next few years, all of whom will be able to shoulder the surgical workload in the country in a professional manner.

\section{Way Forward}

The establishment of the postgraduate program in general surgery within the country has been a boon in addressing the present human resource shortage in the field of surgery. However, Bhutan as a small country stands at the risk of overproduction and saturation of health professionals including general surgeons in next 5-7 years.

Therefore, it is imperative that the university seriously look into the following measures in order to address this looming concern:

- Establish a collaborative and coordinated mechanism to ensure that the university produces graduates based on the needs of the country and the Ministry of Health

- Establish affiliations with certification boards/colleges in the UK, USA, Australia, and Canada where the sur- 
gery graduates can explore for employment opportunities in next $7-10$ years

- Explore for mechanisms to enhance employment possibilities for its graduates

- Initiate enrollment of foreign students

\section{Declarations}

Conflict of Interest The authors declare no competing interests.

\section{References}

1. The Constitution of the Kingdom of Bhutan (2008), art.9, cl.21

2. Thinley S, Tshering P, Wangmo K, Wangmo K, Wangchuk N. et al. The Kingdom of Bhutan health system review. Health Systems in Transition Vol. 7 No. 2, 2017.,World Health Organization. Regional office for South-East Asia. https://apps.who.int/iris/handle/10665/ 255701

3. Ministry of health. Annual health Bulletin, (2021). Ministry of health, Royal government of Bhutan

4. Tenzin K et al (2018) Curriculum for postgraduate medicine in Bhutan's only medical university: time for need-based curricula, review, development and implementation. South-East Asian J Med Educ 3(12):8-11

5. Faculty of Postgraduate Medicine (2018) Curriculum for general surgery. KGUMSB

6. Tenzin K et al (2019) Effect of use of direct observation of procedural skills for assessment for learning in obstetrics and gynaecology postgraduate students at Medical University, Bhutan: a prospective study. Bhu Health J 5(1):9-14

Publisher's Note Springer Nature remains neutral with regard to jurisdictional claims in published maps and institutional affiliations. 